\title{
Adverse Events to Dietary Supplements Causing Emergency Department Visits
}

\section{Compulsive Masturbation Due to Pramipexole}

\section{Metformin-Induced Lactic Acidosis Masquerading As an Acute Myocardial Infarction}

\author{
Michael A. Mancano, PharmD*
}

\begin{abstract}
The purpose of this feature is to heighten awareness of specific adverse drug reactions (ADRs), discuss methods of prevention, and promote reporting of ADRs to the US Food and Drug Administration's (FDA's) MEDWATch program (800-FDA-1088). If you have reported an interesting, preventable ADR to MEDWATCH, please consider sharing the account with our readers. Write to Dr. Mancano at ISMP, 200 Lakeside Drive, Suite 200, Horsham, PA 19044 (phone: 215-707-4936; e-mail: mmancano@temple.edu). Your report will be published anonymously unless otherwise requested. This feature is provided by the Institute for Safe Medication Practices (ISMP) in cooperation with the FDA's MedWATCH program and Temple University School of Pharmacy. ISMP is an FDA MedWATch partner.
\end{abstract}

\section{UNEQUAL SIZED PUPILS DUE TO ESCITALOPRAM}

An 18-year-old female student complained of anxiety while studying for her college entrance examination. Her symptoms, along with anxiety while studying, were unwillingness, fatigue, and insomnia lasting for 6 months. Her psychiatric, memory, and intelligence assessments were normal, however her affect and mood were anxious. Laboratory tests and her physical examination were unremarkable. The patient was diagnosed with generalized anxiety disorder and started on escitalopram (Lexapro) $5 \mathrm{mg}$ daily for 3 days and titrated up to $10 \mathrm{mg}$ daily for 4 days. On the seventh day of escitalopram therapy, anisocoria was observed and the patient was seen by an ophthalmologist.
Anisocoria is a condition in which the patient exhibits unequal pupil size under the same light conditions. Her eye examination revealed a right pupil diameter of $9 \mathrm{~mm}$ and a left pupil diameter of $5 \mathrm{~mm}$ with room light. The patient's pupillary responses were equal with light exposure. The ophthalmologist reported that the patient's ocular examination was normal except for the anisocoria. The patient did not have a history of anisocoria. The patient was then referred for neurology and neurosurgery consultations; however there were no abnormal neurologic findings.

Escitalopram was discontinued; after 4 days, the patient's pupils returned to normal size. The patient asked to be reinitiated on escitalopram $5 \mathrm{mg}$ daily for

${ }^{*}$ Chair and Clinical Professor, Department of Pharmacy Practice, Temple University School of Pharmacy, Philadelphia, Pennsylvania; Clinical Advisor, Institute for Safe Medication Practices, Horsham, Pennsylvania 
her anxiety, but after 6 days of treatment her anisocoria again developed. At this time, escitalopram was discontinued and venlafaxine was started at $37.5 \mathrm{mg}$ daily and titrated up to $150 \mathrm{mg}$ daily. After 7 months of follow-up, the patient tolerated venlafaxine well and anisocoria did not recur.

The authors emphasize that even though anisocoria is not a life-threatening condition, it is a symptom of a number of life-threatening conditions. Anisocoria can occur in patients with intracranial aneurysm, ischemia, high intracranial pressure, brain tumors, and head trauma, which can all paralyze the oculomotor nerve. Severe illnesses and various anticholinergic and sympathomimetic drugs may also cause anisocoria and mydriasis. The authors cite that anisocoria and mydriasis have occurred with fluvoxamine, bupropion, paroxetine, and sertraline. The authors hypothesized that the patient's anisocoria may have been due to anticholinergic features of escitalopram.

Yucel A, Yucel N, Ibis A, et al. Anisocoria associated with escitalopram. J Clin Psychopharmacol. 2015;35(4):483-484.

\section{ADVERSE EVENTS TO DIETARY SUPPLEMENTS CAUSING EMERGENCY DEPARTMENT VISITS}

A nationally representative surveillance study was conducted utilizing the National Electronic Injury Surveillance System (NEISS) with data from 63 representative emergency departments. Data concerning adverse events due to dietary supplements were obtained from the years 2004 through 2013. This analysis included herbal or complementary nutritional products (including botanicals, microbial additives, and amino acids) and micronutrients (vitamins and minerals) but excluded products that are typically considered to be foods or drinks (eg, energy drinks, herbal tea beverages). Additional products that are often utilized by consumers for complementary health but do not fall under the regulatory definition of dietary supplement (eg, topically administered herbal or homeopathic products) were also included in the analysis.

The researchers evaluated their data a variety of ways and uncovered a number of interesting observations. They were able to project that an average of 23,005 emergency department visits for adverse events due to dietary supplements occur annually, with 2,154 patients being admitted to the hospital. The mean age of patients treated in the emergency department was 32 years, with patients over the age of 65 years more likely to be hospitalized. One-fifth of the ingestions resulting in an emergency department visit were for supplement-related adverse events involving unsupervised ingestions in children. The types of products ingested by unsupervised children were micronutrient products including vitamins, iron supplements, weight loss supplements, and supplements for sleep, sedation, or anxiolysis. When excluding the unsupervised minor data, $65.9 \%$ of emergency department visits were due to single herbal or complementary nutritional products. A weight loss product was implicated in $25.5 \%$ of emergency department visits and an energy product in $10 \%$ of visits.

The researchers evaluated the sex of the patient in conjunction with the most common type of product causing an emergency department visit. Adverse events to weight-loss products accounted for $30.4 \%$ of female emergency department visits, whereas these products only accounted for $17.6 \%$ of male visits. However, sexual enhancement products or bodybuilding products caused $14.1 \%$ of male emergency department visits with too few cases to evaluate for females. When the patients were evaluated by age, excluding ingestions by unsupervised children, $67.3 \%$ of patients 4 years of age and younger and $62.7 \%$ of patients 65 years and older presented to the emergency department with an adverse event related to micronutrient ingestion. These micronutrients are multivitamins, single entity vitamins, iron, calcium, potassium, and single entity minerals. Among adults 65 years of age and older, 3 specific micronutrients were implicated in almost one-third of ingestions: irons, calcium, and potassium. Fifty percent of patients between the ages of 5 to 19 years and 20 to 34 years had weight loss products or energy products as the primary cause of their emergency department visit.

The researchers evaluated the symptoms that the patients reported as causing their emergency department visit. Cardiac symptoms such as palpitations, chest pain, and tachycardia were the most common symptoms associated with weight-loss products and energy products. These cardiac symptoms occurred in $71.8 \%$ of patients who presented to the emergency department after having ingested a weight-loss or energy product. Cardiac symptoms were experienced in $49.8 \%$ of emergency department visits attributed to bodybuilding products and in $37.3 \%$ of patients utilizing sexual-enhancement products. The most common adverse effects from most micronutrients (excluding iron, calcium, and potassium) were mildto-moderate allergic reactions in $40.6 \%$ of patients and swallowing problems (combination of choking 
and pill-induced dysphagia or globus) in $41 \%$ of patients. Swallowing problems that caused the most emergency department visits involved the use of calcium products, whereas abdominal symptoms such as nausea, vomiting, and abdominal pain were common with iron or potassium product ingestion. When evaluating the age of patients who experienced swallowing problems, it was noted that patients between the ages of 6 and 64 years were not commonly experiencing swallowing problems. However among patients older than 65 years, $83.1 \%$ of emergency department visits for supplement-induced swallowing problems involved micronutrients.

The authors of this research point out that unlike over-the-counter or prescription medications, the identification of adverse effects on dietary supplement packaging is not required. Clinicians should educate patients about potential adverse effects of dietary supplements.

Geller AI, Shehab N, Weidle NJ, et al. Emergency department visits for adverse events related to dietary supplements. New Engl J Med. 2015;373:1531-1540.

\section{COMPULSIVE MASTURBATION DUE TO PRAMIPEXOLE}

A 55-year-old female reported compulsive masturbation, several times daily, almost every day. This activity was in stark contrast to her sexual behavior over the previous 20 years; during that time she had no boyfriends or sexual partners and was at peace with her celibacy. During her time of compulsive masturbation, she did not seek a sexual partner. The patient's medication history for the treatment of depression is extensive. She had been treated for 9 years with a tricyclic antidepressant and 5 years with tranylcypromine. Due to decreased efficacy for the last 19 years, she had received high doses of serotonin and norepinephrine reuptake inhibitors augmented with lithium or bupropion plus lamotrigine. Recently the patient had experienced a return of her depressive symptoms and she received augmentation with pramipexole (Mirapex) $1 \mathrm{mg}$ daily, with temporary success. After approximately 6 months of therapy, her pramipexole dosage had to be increased to $2 \mathrm{mg}$ daily; for the next 3 months, the patient experienced compulsive masturbation. Pramipexole was discontinued and the compulsive behavior ceased and has not recurred over the past year.

In analyzing this patient's case, the authors point out that pramipexole has been used as adjunctive treatment for major depression in small clinical trials that produced inconsistent benefits. Pramipexole is a dopamine agonist with selective affinity for dopamine receptors of the $\mathrm{D}_{2}$ subfamily, particularly the $\mathrm{D}_{3}$ receptor subtype. Dopamine receptor agonists have been associated with potentially serious impulse control disorders manifesting as hypersexuality, pathological gambling, compulsive shopping, excessive hobbying, binge eating, and repetitive handling and examining of mechanical objects. In patients with Parkinson's disease who received dopamine agonists, approximately $14 \%$ of patients experience impulse control behavior, with $3 \%$ displaying compulsive sexual behaviors.

The authors explain that patients with Parkinson's disease with a history of compulsive disorders, personal or family history of obsessive-compulsive disorders, impulsive personality, bipolar disorder, alcoholism, drug abuse, and other addictions are at higher risk for compulsive behavior. Although the patient in this case did not have Parkinson's disease, she did have a history of stimulant abuse approximately 30 years prior and this may have contributed to her risk of compulsive behavior. They note that there was a clear dose-response relationship between pramipexole and the compulsive sexual behavior the patient displayed, as there was no compulsive masturbation displayed during the 6 months the patient received pramipexole $1 \mathrm{mg}$ daily. The authors recommend that before initiating a dopamine agonist, patients should be evaluated for potential risk factors for compulsive behavior and patients and caregivers should be warned of the risk of compulsive behavior with dopamine agonist therapy.

Rocha FL, Hara C. Compulsive masturbation with pramipexole for antidepressant augmentation in major depression a case report. J Clin Psychopharmacol. 2015;35(4):484-485.

\section{METFORMIN-INDUCED LACTIC ACIDOSIS MASOUERADING AS AN ACUTE MYOCARDIAL INFARCTION}

A 52-year-old female presented to the emergency department with altered mental status. Earlier in the day, the patient had complained of not feeling well and having decreased energy. She also complained of chest pain and had vomited several times. After she had become unarousable, her significant other called 911. When paramedics arrived, she was obtunded with a blood sugar of $30 \mathrm{mg} / \mathrm{dL}$ (normal fasting value, $65-110 \mathrm{mg} / \mathrm{dL}$ ). She had a decreased heart rate of $52 \mathrm{bpm}$ and was hypotensive with a systolic blood pressure of $62 \mathrm{~mm} \mathrm{Hg}$. She was given normal saline and $25 \mathrm{~g}$ of $50 \%$ dextrose, and her blood glucose 
rose to $306 \mathrm{mg} / \mathrm{dL}$. The patient then reported she was short of breath and thought she was going blind. A 12-lead ECG was suggestive of a posterolateral STelevation myocardial infarction.

When the patient arrived at the hospital, she was confused and groggy. She could answer simple questions but was unable to follow simple commands. She was delirious with persistent mumbling speech and in a general state of agitation. Her initial blood pressure was $80 / 50 \mathrm{~mm} \mathrm{Hg}$, heart rate $68 \mathrm{bpm}$, respiratory rate 24 , and bladder temperature of $28.8^{\circ} \mathrm{C}\left(83.8^{\circ} \mathrm{F}\right)$. A repeat ECG revealed persistent ST-segment abnormalities, however the following lab results caused her imminent cardiac catheterization to be placed on hold: sodium $128 \mathrm{mEq} / \mathrm{L}$ (normal value, $135-147 \mathrm{mEq} / \mathrm{L}$ ), potassium $6.1 \mathrm{mEq} / \mathrm{L}$ (normal value, $3.5-5 \mathrm{mEq} / \mathrm{L}$ ), chloride $89 \mathrm{mEq} / \mathrm{L}$ (normal value, $95-107 \mathrm{mEq} / \mathrm{L}$ ), bicarbonate $3 \mathrm{mEq} / \mathrm{L}$ (normal value, 22-26 mEq/L), creatinine $8.7 \mathrm{mg} / \mathrm{dL}$ (normal value, female 0.6-1.2 $\mathrm{mg} / \mathrm{dL}$; patient's baseline, $0.6-0.7 \mathrm{mg} / \mathrm{dL}$ ), lactate 13.5 $\mathrm{mEq} / \mathrm{L}$ (normal value, $0.5-2.2 \mathrm{mEq} / \mathrm{L}$ ), and glucose $226 \mathrm{mg} / \mathrm{dL}$. Her anion gap was $36 \mathrm{mEq} / \mathrm{L}$ (normal value, $3-11 \mathrm{mEq} / \mathrm{L}$ ). A venous blood gas revealed a $\mathrm{pH}$ of 6.73 (normal venous value, 7.32-7.42), pCO2 $27 \mathrm{~mm} \mathrm{Hg}$ (normal venous value, $28-48 \mathrm{mmHg}$ ), bicarbonate $3 \mathrm{mEq} / \mathrm{L}$ (normal venous value, 19-25 $\mathrm{mEq} / \mathrm{L}$ ) and $\beta$-hydroxybutyrate less than $6 \mathrm{mmol} / \mathrm{L}$ (normal value, 0.4-0.5 mmol/L). Based on the lab results, the treating physician thought it was possible that the severe metabolic imbalances were responsible for the patient's ECG changes and canceled the cardiac catheterization.

Treatment was initiated with $100 \mathrm{mEq}$ sodium bicarbonate for the patient's hyperkalemia and severe metabolic acidosis, and the patient was intubated. Due to the patient's hypotension with a SBP of 50 to $60 \mathrm{~mm} \mathrm{Hg}$, she was given $4 \mathrm{~L}$ of normal saline and a norepinephrine infusion. The patient was also rewarmed externally and internally with an intravascular heat-exchanger catheter.

The patient was evaluated via CT scan for head abnormalities and a pulmonary embolism, and both were ruled out by negative CT results. At this time it was unclear what the patient's major problem was, so she was treated empirically for meningitis with dexamethasone, ceftriaxone, acyclovir, and vancomycin. A lumbar puncture was performed, which revealed glucose of $58 \mathrm{mg} / \mathrm{dL}$ (normal value, $50-75 \mathrm{mg} / \mathrm{dL}$ ) and cell count of 1 cells $/ \mathrm{mm}^{3}$ (normal value, $<5$ cells $/ \mathrm{mm}^{3}$ ). Her initial troponin was elevated at $0.134 \mathrm{ng} / \mathrm{mL}$ (normal value, $<0.04 \mathrm{ng} / \mathrm{mL}$ ). Her blood was drawn for a toxic alcohol screen; with further resuscitation, her SBP stabilized at 80 to $90 \mathrm{~mm} \mathrm{Hg}$, while her temperature improved to $33^{\circ} \mathrm{C}\left(91.4^{\circ} \mathrm{F}\right)$. A repeat ECG showed an improved ST segment elevation. At this time, the patient was transferred to the medical intensive care unit and received emergent dialysis.

A repeat ECG at 7 hours after her admission revealed that all ST segment abnormalities had resolved. A cardiology consult revealed that her cardiac presentation was not consistent with acute coronary syndrome but rather myocardial ischemia due to an imbalance in supply and demand and not coronary artery disease. Toxicology screens were negative for toxic alcohols, ethanol, acetaminophen, salicylates, and all drugs of abuse. A metformin concentration was ordered by the emergency department physician, and it was sent out to an outside laboratory for quantitative high-performance liquid chromatography tandem mass spectrometry. The metformin level was later reported to be elevated at $51 \mu \mathrm{g} / \mathrm{mL}$ (therapeutic range, $1-2 \mu \mathrm{g} / \mathrm{mL}$ ). Based on the available objective information, the presumed cause of her critical illness was metformin-associated lactic acidosis (MALA) due to chronic use, with a preceding gastrointestinal illness precipitating acute renal injury, subsequent metformin accumulation, and life-threatening metabolic acidosis.

During her hospital stay, the patient received hemodialysis for 5 days until adequate urine output returned. Norepinephrine was continued for 6 days and the patient was treated with broad-spectrum antibiotics for 7 days. The patient was extubated on hospital day 14, and she was discharged on hospital day 21 neurologically intact including full return of her vision. At discharge, the patient's metformin was not reinitiated and insulin glargine therapy was started.

The authors point out that, "In cases of unintentional metformin toxicity, MALA typically presents as a subacute illness with nonspecific symptoms, such as malaise, nausea, vomiting, diarrhea, reduced oral intake, abdominal pain or myalgia. As the illness becomes severe, mental status changes and cardiovascular collapse can occur. The mortality rate in unintentional toxicity is estimated to be $25-50 \%$." The authors also noted that this case is unique in that the patient reported transient blindness, which was most likely due to the profound acidosis with hypoglycemia and hypotension as contributing factors.

White S, Driver BE, Cole JB. Metformin-associated lactic acidosis presenting as acute ST-elevation myocardial infarction. J Emerg Med. 2016;50(1):32-36. 